\title{
Correlation of Glycated Hemoglobin (HbA1c) with Different Cardiovascular Risk Factors in Non-diabetic Patients
}

\author{
Abdul Ghaffar Memon ${ }^{*}$, Muhammad Khan Soomro and Mubashir Ali Kolachi
}

Department of Cardiology, Liaquat University of Medical and Health Sciences Jamshoro/Hyderabad, Pakistan

"Corresponding author: Abdul Ghaffar Memon, Department of Cardiology, Liaquat University of Medical and Health Sciences Jamshoro/Hyderabad, Pakistan, Tel: +254722863595; E-mail: gmemon680@gmail.com

Rec date: April 16, 2016; Acc date: May 01, 2016; Pub date: May 10, 2016

Copyright: ( 2016 Memon AG, et al. This is an open-access article distributed under the terms of the Creative Commons Attribution License, which permits unrestricted use, distribution, and reproduction in any medium, provided the original author and source are credited.

\begin{abstract}
Objective: To determine the HbA1c levels correlation with cardiovascular events among non-diabetic patients.

Material and methods: The prospective study was conducted at cardiology department of Liaquat University of medical and health science. Total 130 cases were selected in this study. All the cases were selected with different cardiovascular diseases and having age more than 40 years. All the cases having multiple risk factors of cardio vascular disease were excluded from the study. $\mathrm{HbA1}$ c blood test was send to the diagnostic research lab of Liaquat University of Medical and health science. HbA1c was recorded in the proforma according to risk factors. All the data regarding $\mathrm{HbA} 1 \mathrm{c}$ level and its related cardiovascular risk were entered in the proforma.
\end{abstract}

Results: Mean age of the patients was found as Mean+SD $=42.4+5.43$ years. While majority of the cases 45 $(42.6 \%)$ were found with age group of 51-60 years. Male were found in the majority $64 \%$ and female were found $36 \%$ in the cases. According to the cardiovascular risk factors smoking was found most common in $30.76 \%$ of the cases, 2nd most common risk factors were found hypertension and dyslipidemia, with percentage of $25.38 \%$ and $23.07 \%$ respectively. In this series $\mathrm{HbA} 1 \mathrm{c}$ associated with hypertension, obesity and dyslipidemia.

Conclusion: We have found that HbA1c level is highly correlated with risk factors of CVD, especially in obesity, hypertension and dyslipidemia amongst individuals without DM.

Keywords: HbA1c; CVD; Non diabetic

\section{Introduction}

Hemoglobin glycation, found via percent HbAlc, was initially practiced clinically before 30 years to reviewchronic hyperglycemia degree in diabetic cases in those whose values reveal weighted average levels of glucose above former 3-months [1]. Over bygone three decades, prominent $\mathrm{HbA} 1 \mathrm{c}$ is determinedly connected to risk of longterm complications of micro vessels and HbAlc evaluation is currently used far and wide to monitor proficient glycemic control as diabetes care cornerstone. With presentation of reference technique consistency, issues concerning high inter-assay as well as inter-laboratory analytic inconsistency have been greatly overwhelmed such that during 2002, $98 \%$ of United States laboratories surveyed practiced consistent techniques [2]. Given these positive performance uniqueness, current analytical efforts have endeavored to extend the HbAlc part as an increasing glycaemic exposure index in cardiovascular risk and diabetes valuation in non-diabetic cases. Numerous studies have assessedHbA1c levels ability to forecast prospect type 2 diabetes among pre-diabetic, high-risk patients $[3,4]$ and up to date data propose that HbAlc can possibly as well be handy in the detection of risk for incidental cardiovascular events [5,6]. Significantly, whether an only $\mathrm{HbA} 1 \mathrm{c}$ assessment can be applied in this purpose, stays uncertain and future population-established studies of the cases at low to moderate risk are exceptional. In a former periodical case-control investigation [7], we established that a high level of HbAlc was a univariated predictor of incidental cardiovascular events, however this influence was not considerable subsequent to adjustment for rest of the risk factors cardiovascular disease. Though, we did not scrutinize nonlinear threshold consequences that can possibly have prognostic importance as was demonstrated in several future studies of incident cardiovascular and plasma glucose events $[8,9]$ and as a minimum one finding of cardiovascular mortality and HbAlc.5Henceour purpose to evaluate the levels of $\mathrm{HbAlc}$ correlation with cardiovascular events in non-diabetic patients.

\section{Methodology}

This prospective study was performed at cardiology department of Liaquat University of medical and health science. Total 130 cases were selected in this study. All the cases were selected with different cardiovascular diseases and having age more than 40 years. Each subject experienced a complete physical assessment, and a selfadministered survey presented data concerning medical history, drinking habits and smoking, physical activity of free time, medication and healthcare system contact history. BP was calculated through sphygmomanometer. Cholesterol and plasma glucose levels were calculated in venous blood samples while non-fasting. ECG was documented at rest during supine pose, and results were delineated. HbAlc measurement for haemolysed entire blood collection was done at the initial visit. All the cases those having multiple risk factors of cardio vascular disease were excluded from the study. HbAlc blood test was send to the diagnostic research lab of Liaquat University of Medical and health science. HbAlc was recorded in the proforma 
Page 2 of 3

according to risk factors. All the data regarding HbAlc level and its related cardiovascular risk were entered in the proforma.

\section{Results}

Mean age of the patients was found as Mean $+\mathrm{SD}=42.4+5.43$ years. While majority of the cases $45(42.6 \%)$ were found with age group of 51-60 years, following by $40-50$ years, $61-70$ years and $>70$ years with the percentage of $40(26.0 \%), 30(20.0 \%)$ and $15(5.3 \%)$ patients respectively (Table 1 ).

\begin{tabular}{|l|l|}
\hline Gender & Frequency (\%) \\
\hline Mean + SD & $42.4+5.43$ \\
\hline Age groups & \\
\hline $40-50$ & $40(26.0 \%)$ \\
\hline $51-60$ & $45(42.6 \%)$ \\
\hline $61-70$ & $30(20.0 \%)$ \\
\hline$>70$ & $15(5.3 \%)$ \\
\hline
\end{tabular}

Table 1: Age distribution $\mathrm{N}=130$.

Male were found in the majority $64 \%$ and female were found $36 \%$ in the cases (Figure 1).

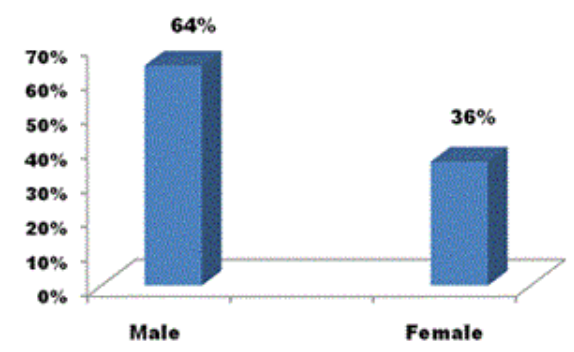

Figure 1: Gender distribution N=130.

According to the cardiovascular risk factors smoking was found most common in $30.76 \%$ of the cases, 2 nd most common risk factors were found hypertension and dyslipidemia, with percentage of $25.38 \%$ and $23.07 \%$ respectively (Table 2 ).

\begin{tabular}{|l|l|l|}
\hline CVD Risk Factors & Frequency & $\%$ \\
\hline Hypertensive & 33 & $25.38 \%$ \\
\hline Obesity & 15 & $11.53 \%$ \\
\hline Smoking & 40 & $30.76 \%$ \\
\hline Alcohol consumption & 12 & $9.23 \%$ \\
\hline Family history & 10 & $7.69 \%$ \\
\hline Dyslipidemia & 30 & $23.07 \%$ \\
\hline
\end{tabular}

Table 2: CVD risk factors distribution $\mathrm{N}=130$
In this series $\mathrm{HbAlc}$ associated with hypertension, obesity and dyslipidemia (Table 3).

\begin{tabular}{|l|l|l|l|l|}
\hline CVD risk factors & HbA1c & HbA1c & HbA1c & HbA1c \\
\hline & $\mathbf{5 . 0}$ & $\mathbf{5 . 1 - 5 . 4}$ & $\mathbf{5 . 5 - 6 . 4}$ & $\leq 6.5$ \\
\hline Hypertensive $(\mathrm{n}=33)$ & 16 & 9 & 7 & 1 \\
\hline Obesity $(\mathrm{n}=15)$ & 5 & 3 & 3 & 4 \\
\hline Smoking $(\mathrm{n}=40)$ & 19 & 12 & 11 & 2 \\
\hline Alcohol consumption $(\mathrm{n}=12)$ & 5 & 3 & 3 & 1 \\
\hline Family history $(n=10)$ & 3 & 3 & 3 & 1 \\
\hline Dyslipidemia $(n=30)$ & 9 & 11 & 5 & 5 \\
\hline
\end{tabular}

Table 3: HbA1c distribution according to CVD risk factors $\mathrm{N}=130$.

\section{Discussion}

In this study, we found that $\mathrm{HbAlc}$ is associated with CVD development among nonediabetic cases. Thus, cases with no DM with levels of $\mathrm{HbAlc}$ in normalrange of reference had an escalated risk of CVD development. In this finding patients' mean age was found as Mean $+\mathrm{SD}=42.4+5.43$ years. While majority of the cases $45(42.6 \%)$ were found with age group of 51-60 years. O'Sullivan et al. [10] reported that 72 years was the mean age and 59\% were men. In this series male were found in the majority $64 \%$ and female were found $36 \%$ in the cases. Masood et al., [11] as well observed men in majority that is $75 \%$ as compared to women $25 \%$. In this study according to the cardiovascular risk factors smoking was found most common in $30.76 \%$ of the cases, 2nd most common risk factors were found hypertension and dyslipidemia, with percentage of $25.38 \%$ and $23.07 \%$ respectively. A finding on disease of coronary artery, exhibited that the overall $42 \%$ cases were hypertensive [12]. During the study of Arvind kumar et al., observed elevated smoking rates as a risk factor and as well as men in majority were involved [13]. In Masood et al. finding, 1186 (53.8\%) cases were hypertensive, sixty six (41.3\%) were smokers, fifty eight (36.3\%) retained diabetes mellitus, thirty eight $(23.8 \%)$ cases retained family ischemic cardiac disease history and forty $(25 \%)$ cases retained dyslipidemia. In this series $\mathrm{HbAlc}$ associated with hypertension, obesity and dyslipidemia. Raised risk of CVD was observed in three uppermost HbAlc quartiles. In the uppermost quartile, risk was obvious following HbAlc levels and the development of DM. In current study, we exhibit that HbAlc is related to CVD risk within our populace. Preceding studies investigating $\mathrm{HbAlc}$ role as a DM predictor have conventionally been carried out in high-risk [14-16] heterogeneous or small populaces $[17,18]$. In current study, we observed an obvious association in future CVD risk and HbA1c levels in common population. Our outcomes did not widen to discovery of statistically considerable relations in incident CVD events and HbA1c. Moreover, macro vascular complications development was not associated to levels of HbAlc in these matters. This is contrary to the outcomes of prior epidemiological cohort findings, which though in short of standardized $\mathrm{HbAlc}$ measurements and risk factors adjustment. However, interventional findings have exhibited slight or a probable harmful outcome of reducing HbAlc to avoid CVD events in cases which are nondiabetic $[17,18]$ emphasize that either the association between DM and CVD (as well as arterial disease) is causal or not, remains mysterious and certainly that $\mathrm{HbA1c}$ can possibly be distal to genuine pathological outcomes related to cardiovascular 
Citation: Memon AG, Soomro MK, Kolachi MA (2016) Correlation of Glycated Hemoglobin (HbA1c) with Different Cardiovascular Risk Factors in Non-diabetic Patients. J Cardiovasc Dis Diagn 4: 243. doi:10.4172/2329-9517.1000243

Page 3 of 3

disease. Among nondiabetic cases, the part of HbAlc is uncertain Selvin et al. [19] mentioneda relationship in CVD and HbAlc in a community-based finding of nondiabetic individuals in heterogeneous population of America. Other authors reported alike outcomes, though inconsistently $[20,21]$.

\section{Conclusion}

In the given study, we established that level of HbAlc is greatly associated to the CVD development amongst case without DM, especially in the cases having obesity, dyslipidemia and old age. More studies with big sample size are required for further confirmation.

\section{References}

1. Tahara Y, Shima K (1995) Kinetics of HbAlc, glycated albumin, and fructosamine and analysis of their weight functions against preceding plasma glucose level. Diabetes Care 18: 440-447.

2. Little RR (2003) Glycated hemoglobin standardization-National Glycohemoglobin Standardization Program (NGSP) perspective. Clin Chem Lab Med 41: 1191-1198.

3. Little RR, England JD, Wiedmeyer HM, Madsen RW, Pettitt DJ, et al. (1994) Glycated haemoglobin predicts progression to diabetes mellitus in Pima Indians with impaired glucose tolerance. Diabetologia 37: 252-256.

4. Ko GT, Chan JC, Tsang LW, Cockram CS (2000) Combined use of fasting plasma glucose and $\mathrm{HbAlc}$ predicts the progression to diabetes in Chinese subjects. Diabetes Care 23: 1770-1773.

5. Khaw KT, Wareham N, Luben R, Bingham S, Oakes S, et al. (2001) Glycated haemoglobin, diabetes, and mortality in men in Norfolk cohort of european prospective investigation of cancer and nutrition (EPICNorfolk). BMJ 322: 15-18.

6. Khaw KT, Wareham N, Bingham S, Luben R, Welch A, et al. (2004) Association of hemoglobin A1c with cardiovascular disease and mortality in adults: the European prospective investigation into cancer in Norfolk. Ann Intern Med 141: 413-420.

7. Blake GJ, Pradhan AD, Manson JE, Williams GR, Buring J, et al. (2004) Hemoglobin Alc level and future cardiovascular events among women. Arch Intern Med 164: 757-761.

8. Balkau B, Shipley M, Jarrett RJ, Pyorala K, Pyorala M, et al. (1998) High blood glucose concentration is a risk factor for mortality in middle-aged nondiabetic men. 20-year follow-up in the Whitehall Study, the Paris Prospective Study, and the Helsinki Policemen Study. Diabetes Care 21: 360-367.
9. Scheidt-Nave C, Barrett-Connor E, Wingard DL, Cohn BA, Edelstein SL (1991) Sex differences in fasting glycemia as a risk factor for ischemic heart disease death. Am J Epidemiol 133: 565-576.

10. O'Sullivan CJ, Hynes N, Mahendran B, Andrews EJ, Avalos G, et al. (2006) Haemoglobin Alc (HbA1C) in non-diabetic and diabetic vascular patients. Is $\mathrm{HbA} 1 \mathrm{C}$ an independent risk factor and predictor of adverse outcome? Eur J Vasc Endovasc Surg 32: 188-197.

11. Masood A, Ali Naqvi M, Sohail S (2009) In-hospital outcome of acute myocardial infarction in correlation with thrombolysis in myocardial infarction'risk score. J Ayub Med Coll Abbottabad 21.

12. Gupta R, Prakash H, Majumdar S, Sharma S, Gupta VP (1995) Prevalence of coronary heart disease and coronary risk factors in an urban population of Rajasthan. Indian Heart J 47: 331-338.

13. Kumar A, Garg S, Gupta HL (2005) A Study of Prevalence of Risk Factors for Coronary Artery Diseases in Asymptomatic Middle Aged and Elderly Subjects. Hypertension 14: 17.

14. Narayan KM, Hanson RL, Pettitt DJ, Bennett PH, Knowler WC (1996) A two-step strategy for identification of high-risk subjects for a clinical trial of prevention of NIDDM. Diabetes Care 19: 972-978.

15. van't Riet E, Rijkelijkhuizen JM, Alssema M, Nijpels G, Stehouwer CD, et al. (2012) HbAlc is an independent predictor of non-fatal cardiovascular disease in a Caucasian population without diabetes: a 10-year follow-up of the Hoorn Study. European Journal of Preventive Cardiology 19: 23-31.

16. Bonora E, Kiechl S, Mayr A, Zoppini G, Targher G, et al. (2011) Highnormal $\mathrm{HbAlc}$ is a strong predictor of type 2 diabetes in the general population. Diabetes Care 34: 1038-1040.

17. Action to Control Cardiovascular Risk in Diabetes Study Group, Gerstein HC, Miller ME, Byington RP, Goff DC Jr, et al. (2008) Effects of intensive glucose lowering in type 2 diabetes. N Engl J Med 358: 2545-2559.

18. Nissen SE, Wolski K (2007) Effect of rosiglitazone on the risk of myocardial infarction and death from cardiovascular causes. N Engl J Med 356: 2457-2471.

19. Selvin E, Steffes MW, Zhu H, Matsushita K, Wagenknecht L, et al. (2010) Glycated hemoglobin, diabetes, and cardiovascular risk in nondiabetic adults. N Engl J Med 362: 800-811.

20. Park S, Barrett-Connor E, Wingard DL, Shan J, Edelstein S (1996) GHb is a better predictor of cardiovascular disease than fasting or postchallenge plasma glucose in women without diabetes: the Rancho Bernardo Study. Diabetes Care 19: 450-456.

21. Lawlor DA, Fraser A, Ebrahim S, Smith GD (2007) Independent associations of fasting insulin, glucose, and glycated haemoglobin with stroke and coronary heart disease in older women. PLoS Med 4: e263. 